\title{
Dental Examination
}

National Cancer Institute

\section{Source}

National Cancer Institute. Dental Examination. NCI Thesaurus. Code C158323.

A systematic evaluation of the mouth, face, and neck, which may include tooth counting, cleaning and visual assessments for abnormalities such as caries, gum disease, oral cancer, and structural malformations. 